\title{
O Desenvolvimento do Setor Farmacêutico: a Caminho de uma Estratégia Centrada na Inovação*
}

Jorge de Paula Costa Avila

Vice-Presidente do Instituto Nacional de Propriedade Industrial

\section{RESUMO}

O presente artigo discute objetivos e estratégias para a implementação de uma das prioridades da política industrial e tecnológica: o desenvolvimento da indústria farmacêutica brasileira. Suas principais conclusões, justificadas ao longo do trabalho, são: o objetivo da política para o complexo farmacêutico não deve ser a simples e generalizada substituição de importações, mas a construção, no País, de um ambiente de inovação farmacêutica capaz de oferecer produtos e serviços avançados para o mercado global; e que, face às novas estratégias de $\mathrm{P} \& \mathrm{D}$ das empresas líderes mundiais do setor, que abrem oportunidades para empresas de porte menor, esse objetivo é alcançável mediante ações coordenadas de indução e facilitação. O aperfeiçoamento do sistema nacional de inovação em saúde, o fomento ao desenvolvimento de uma teia de empresas de grande especialização, assim como ao relacionamento desta teia com empresas dotadas de capacidade comercial e de negociação compõem o leque de ações articuladas apresentado

Agradeço às professoras Anna Maria Campos e Ana Célia Castro, aos professores Sergio Salles Filho, Sérgio Queiroz e Antonio Barros de Castro, aos editores da RBI e aos pareceristas anônimos pela contribuição e pelas discussões e comentários que viabilizaram a feitura deste artigo. 
como estratégia eficaz para o aproveitamento das oportunidades apontadas. Os instrumentos disponíveis e as experiências internacionais e nacionais no fomento à inovação e ao investimento são discutidas vis à vis a estratégia proposta, e um programa nacional de desenvolvimento de medicamentos para doenças negligenciadas é sugerido como piloto articulador de uma iniciativa integrada de fomento.

Palavras-Chave | Desenvolvimento Industrial; Inovação; Indústria Farmacêutica; Estratégias de P\&D; Política Industrial e Tecnológica

Códigos JEL | L52; L65; O14; O31; O32

\section{ABSTRACT}

This paper discusses objectives and strategies for implementing one of the priorities of the new Brazilian industrial and technological policy: the development of the national pharmaceutical industry. It arrives to two conclusions: first, that the policy should not aim at simple and generalized import substitution, but at offering technologically advanced products and services to global markets; and second that, due to changes in R\&D strategies, such ambitious objective may be achievable through the coordination of investment, fostering initiatives and policy tools. Improving the national innovation system in the field of health and life sciences, directly helping to create and develop a network of start-ups and to develop its connections with bigger companies is shown as an adequate strategy for such achievement. National and international experiences in fostering innovation are discussed in the light of the suggested strategy, and a National Program to develop medicines for Neglected Deseases is suggested as a pilot experience of such a policy.

KeYwords | Industrial Development; Innovation; Pharmaceutical Industry; R\&D Strategies; Industrial and Tecnology Policies

JEL CODES I L52; L65; O14; O31; O32 


\section{Introdução}

Com seus pontos altos e seus pontos baixos, o papel do Estado na Economia brasileira foi preponderante para o desenvolvimento dos principais segmentos da indústria nacional. Mais do que isso, ele foi fundamental para a superação de barreiras tecnológicas, para o que se utilizou de amplo conjunto de instrumentos, e assumiu, ao menos por longo período inicial, o controle direto das decisões de investimento em muitos setores importantes da Economia (Castro, 1985).

Tal não ocorreu no complexo farmacêutico, embora tenha havido políticas que visavam à criação de empresas privadas, verticalizadas, que deveriam atuar da síntese de fármacos à comercialização de medicamentos acabados. Não esteve embutida na estratégia a intenção de desenvolver fármacos inovadores: o esforço tecnológico concentrou-se na engenharia reversa, realizada, por vezes, com o apoio de universidades e institutos de pesquisa (Queiroz, 1993). Notese que esta arquitetura era coerente com o modelo de economia fechada e de substituição de importações para abastecimento do mercado interno que caracterizou aquela geração de políticas industriais (Castro, 2002). A não concessão de patentes, nem para processos nem para produtos farmacêuticos naquele período, explica a possibilidade de executar-se uma tal política e, talvez, revela as razões pelas quais a inovação farmacêutica não foi incluída entre seus objetivos (Queiroz, 1993), sob esse prisma modesto. Tais tentativas fracassaram em grande medida: o complexo farmacêutico brasileiro é hoje composto por divisões de empresas multinacionais focadas nos elos de menor agregação de valor, por empresas nacionais pouco capitalizadas e, em geral, sem capacidade de inovação (Frenkel, 2002), e por modesto conjunto de pequenas empresas de biotecnologia, pouco articuladas às empresas das duas categorias anteriormente descritas (Avila, 2003). Resultaram, contudo, no desenvolvimento de competências nas universidades e institutos de pesquisa que, em alguma medida, estão até hoje preservadas e talvez tenham contribuído significativamente para o mais recente desenvolvimento de pequenas empresas de maior conteúdo tecnológico (Salles-Filho, 2000).

A Política Industrial, Tecnológica e de Comércio Exterior (PITCE), recentemente anunciada pelo Governo Federal, opera num contexto inteiramen- 
te distinto do que se apresentava à época do II PND (Plano Nacional de Desenvolvimento): o País detém, hoje, parque industrial muito mais complexo e diversificado, e está cada vez mais integrado ao sistema internacional de comércio. Resulta que, diferente das concepções anteriores, seu objetivo central não é a construção de setores, mas sim aumentar a competitividade da indústria brasileira no mercado global por meio do desenvolvimento de capacitaçôes (não apenas fabris) e do incentivo à inovação. Elegeram-se quatro segmentos como de particular interesse na política: bens de capital, eletrônicos, software e fármacos. É trivial notar que os três primeiros segmentos de interesse não constituem prioridades setoriais per se: o interesse neles se deve, claramente, por seus efeitos sistêmicos sobre a indústria. A indústria farmacêutica constitui, portanto, a única prioridade estritamente setorial, numa política de recortes essencialmente horizontais.

Tal escolha pode ser explicada por distintos fatores. Destaque-se, entre eles, a obrigação constitucional de garantir o acesso universal à saúde e a avaliação de que o País dispõe de dois insumos que vêm se tornando fundamentais no campo farmacêutico: grande diversidade biológica e recursos humanos capacitados para a sua manipulação. Além disso, diversos estudos apontam oportunidades que parecem estar surgindo em decorrência da dinâmica tecnológica do setor farmacêutico mundial, que abre cada vez mais espaço para a participação de atores especializados de porte menor em atividades de alto valor agregado, especialmente na produção da inovação (Jungmittag et al., 2000).

Destaque-se, contudo, que os estudos sobre o setor apontam também para a oligopolização contínua em torno dos atuais líderes da indústria mundial (Frenkel, 2002). Parece haver pouca chance de se desenvolverem empresas brasileiras com possibilidades de competir nos principais mercados com as empresas líderes multinacionais. A vantagem destas últimas resulta da capacidade de tomar os riscos elevados envolvidos no longo processo de desenvolvimento de novos fármacos, da capacidade de coordenarem esse processo e do domínio dos canais e técnicas empregados em seu marketing e comercialização. Resultam de acumulação de recursos financeiros e conhecimentos de difícil reprodução a curto e mesmo médio prazos.

Ao longo deste trabalho se formulam e discutem propostas que visam a fomentar o uso dos recursos de que dispomos para o mais amplo aprovei- 
tamento das oportunidades que parecem se abrir. Distinta de outras proposições (ao menos na ênfase), aqui não se postula a implementação de amplo programa de substituição de importações na área farmacêutica, nem tampouco o fomento à criação imediata de grandes empresas integradas de capital nacional no setor farmacêutico. A economia brasileira está hoje aberta ao comércio internacional e deverá abrir-se ainda mais, e o País é signatário de acordos que limitam a possibilidade de engenharias reversas, ao tempo em que detém desenvolvido parque científico. Postula-se, frente a isso, e a meu ver com maior alinhamento para com as demais dimensões da PITCE: o fomento ao desenvolvimento de uma malha sinérgica de empresas inovadoras, de distintos portes e diferentes especializações; o estímulo à cooperação entre as empresas de tal malha e as empresas nacionais de maior porte; e, através destas últimas, ou não, a participação nos programas de pesquisa e nas estratégias comerciais de empresas líderes mundiais. Políticas com esse enfoque não perseguiriam a auto-suficiência na produção de fármacos e medicamentos, que esbarraria em severas restrições patentárias e de marcas no que tange a fármacos de maior valor, e na falta de escala ou de relevância econômica nos demais casos. ${ }^{1}$ Tais políticas perseguiriam, distintamente, a maior geração possível de valor pela especialização em produtos e serviços inovadores, de alta densidade tecnológica, para oferta aos mercados interno e externo coordenadamente. Perseguiriam, com destaque e como mola motriz, o desenvolvimento e a oferta de produtos farmacêuticos relevantes para a população do País (e para outras populaçôes) mas ainda indisponíveis nos mercados, como as drogas e vacinas para doenças ditas negligenciadas e para aquelas passíveis e necessitadas de grande esforço de desenvolvimento de novas terapias e medidas de prevenção, como ocorre com o câncer e a AIDS.

A formulação de estratégias de fomento com tais características são baseadas em ações que tornem o ambiente institucional mais favorável à inovação na área farmacêutica, assim como no desenho de instrumentos adequados à diversidade de atores que dele devem participar. As características gerais de tais estratégias constituem o objeto deste trabalho.

\footnotetext{
A ênfase na balança setorial de comércio presente, p.ex. em Magalhães et al. (2003) pode induzir à conclusão de que se deveria promover a substituição de importações de produtos farmacêuticos de grande consumo apesar do baixo valor. Nas condições atuais, isso representaria, a meu ver, aumento de custo sem qualquer vantagem efetiva, uma vez que outros países, como a Índia e a China, apresentam melhores condições para essa classe de produtos. Seria, portanto, um equívoco.
} 


\section{O desenvolvimento de um ambiente institucional favorável à inovação farmacêutica}

O sistema nacional de inovação em saúde, no Brasil como em todo o mundo, é particularmente complexo. Sua complexidade resulta da teia reguladora que visa assegurar a observância dos princípios éticos e das preocupações com segurança fundamentais nas atividades que afetam a saúde humana (Jungmittag, 2000).

Diversas dimensões são relevantes para a compreensão dos sistemas de inovação em saúde. Malerba e Orsenigo (2001) chamaram a atenção para a estrutura em rede que organiza as relações entre diferentes tipos de empresas, instituições produtoras e disseminadoras de conhecimento, bancos e outras instituiçōes financeiras, instituições reguladoras e consumidores de diferentes naturezas.

Grande complexidade técnica se faz presente nas transações entre esses distintos atores. Em muitos dos elos dessa rede se faz necessária, para permitir a interação, a participação de profissionais e empresas especializadas. O efetivo dinamismo do setor resulta, em grande medida, da qualidade e da fluidez das relações que assim se produzem (Malerba \& Orsenigo, 2001).

Malerba e Orsenigo (2001) observaram a natureza dinâmica dessas relações. Segundo esses autores, a importância dos atores muda ao longo do tempo e evolui de maneira distinta em cada país ou região, inclusive pela entrada de novos participantes e pela contínua construção de novas formas de relacionamento. Mudam também as capacitações requeridas dos atores e, em conseqüência, as estratégias por eles empregadas.

As observaçôes de McKelvey e Orsenigo (2001) sugerem que qualquer abordagem do problema de desenvolvimento do ambiente institucional para tornálo mais favorável à inovação no setor farmacêutico deve ser empreendida com atenção particular à dinâmica que se opera a cada momento e em cada lugar. A criação de um ambiente favorável à interação entre os distintos atores, presentes no cenário nacional ou passíveis de cooptação, constitui o núcleo central desta componente. Cinco aspectos dessa questão são abordados: a defesa da propriedade intelectual, a obtenção de licenças para a produção e comercialização de fármacos no País, o acesso à biodiversidade, a infra-estrutura pública para suporte à pesquisa e os instrumentos de fomento à cooperação.

Cada uma dessas questôes comportaria, em si, um estudo de grandes 
dimensões. O objetivo que aqui se vai perseguir é, tão-somente, o de apontar alguns pontos onde há evidente possibilidade de aperfeiçoamento e, por vezes, sugerir caminhos.

\subsection{A proteção da propriedade intelectual}

Contratos de transferência de tecnologia e cooperação tecnológica ocupam lugar central na nova organização do processo de pesquisa e desenvolvimento de produtos farmacêuticos (Arora et al., 2000). Só é possível firmar tais naturezas de contratos mediante a precisa reserva de direitos entre as partes, $o$ que se deve contar com adequado sistema de proteção da propriedade intelectual (Hullman, 2000). O sistema brasileiro de proteção da propriedade intelectual tem sido apontado como excessivamente moroso quando comparado aos seus congêneres em outros países. Representa, por isso, reconhecida fragilidade do sistema nacional de inovação, a dificultar, especialmente, os relacionamentos entre os brasileiros postulantes de patentes e marcas e seus possíveis parceiros tecnológicos e comerciais. No caso específico das patentes farmacêuticas, o processo é ainda mais complexo do que nos demais setores. Como o INPI (Instituto Nacional da Propriedade Industrial), à época da aprovação da nova Lei de Propriedade Industrial, não tinha experiência com o segmento, instituiu-se na ANVISA (Agência Nacional de Vigilância Sanitária) um grupo técnico ao qual coube se pronunciar sobre a concessão de patentes em adição à análise do INPI. Não é claramente definida na Lei a distribuição de papéis. Uma ação desejável no contexto das políticas para desenvolver o setor farmacêutico nacional, calcadas no fomento à inovação seria, portanto, a ampliação da capacitação dos atores envolvidos e a melhor definição de seus modos de interação, de forma a simplificar o processo de análise e concessões de patentes para fármacos sem torná-lo, necessariamente, menos rigoroso.

Ressalte-se que a questão da propriedade intelectual em fármacos e demais produtos ligados à saúde tem produzido grande controvérsias desde a aprovação de TRIPs $^{2}$ e da decorrente inclusão dos produtos e processos farmacêuticos no escopo do sistema patentário do Brasil e de outros países em de-

2 Trade Related Intellectual Property Rights, acordo firmado pelos países membros quando da criação da Organização Mundial do Comércio - OMC. 
senvolvimento. Na visão de diversas organizações não governamentais relevantes como, por exemplo, a Médicos Sem Fronteiras e a Associação Brasileira Interdisciplinar de AIDS, as patentes sobre produtos farmacêuticos encarecem os produtos sem que haja contrapartida significativa em benefícios para os doentes ao menos nos países em desenvolvimento. $\mathrm{O}$ argumento assevera que tais preços têm inviabilizado o acesso de amplos contingentes de doentes a fármacos modernos, gerando grave problema de saúde pública nos países mais pobres.

Sensível a tais argumentos, a rodada de negociações da OMC que se iniciou em Doha gerou uma declaração (conhecida como Declaração de Doha, disponível em www.wto.org) onde se reafirmam ou consolidam interpretaçóes de diversos princípios presentes em TRIPs, que garantem aos países a possibilidade de conferirem tratamento diferenciado nas questôes patentárias relativas a produtos imprescindíveis para a saúde pública. TRIPs contempla, também desde o princípio, a conhecida "exceção Bolar", que garante a autorização para produzir artigos patenteados, sem pagamentos de royalties, para fins de pesquisa e inovação suplementar, assim como manteve inalterados os critérios substantivos e formais tradicionalmente empregados para a concessão e a caducidade das patentes. Todos esses aspectos encontram eco na legislação brasileira e precisam ser adequadamente levados em conta na condução de uma política de inovação farmacêutica. É importante reafirmar, contudo, que há espaço para a constituição de relações de cooperação tecnológica e comercial voluntária com as empresas multinacionais. Para tanto, a formação de um porta-fólio de patentes e marcas nacionais é imprescindível. As patentes e as marcas detidas por um ator constituem sua principal moeda de negociação na construção de alianças (Teece, 2001).

Quando se tem claro que grande parte da pesquisa farmacêutica efetuada no País ocorre em instituições públicas de pesquisa, também o modo de relacionamento entre essas instituições e as empresas, assim como os próprios critérios de avaliação do sistema acadêmico nacional devem ser apreciados. Dentro do escopo da PITCE, a Lei de Inovação, ora em discussão no Congresso, deverá autorizar maior fluidez no licenciamento de patentes da universidade e institutos públicos para empresas privadas. Incentivar que tal sistema seja operado com eficiência, inclusive tornando-o quesito de avaliação, poderá trazer grande impacto. 


\subsection{O licenciamento de novos produtos farmacêuticos}

Independentemente do rigor das regras para a obtenção de licenças para a produção e comercialização produtos farmacêuticos, que em todo o mundo é cada vez maior, os processos para a sua obtenção podem ser mais ou menos bem engendrados. Por exemplo, o sistema europeu é freqüentemente acusado se ser muito mais complicado, apesar de às vezes menos exigente, do que o sistema norte-americano. Os processos empregados para a concessão de licenças podem ser revisados cuidadosamente, buscando-se evitar, tanto quanto possível, dificuldades desnecessárias.

A normatização desses processos está a cargo da ANVISA e é baseada em um conjunto de disposições em contínuo aperfeiçoamento. Detalhamento maior dos procedimentos foi recentemente publicado para o registro dos chamados fitoterápicos (Resolução RDC 17 de 24/02/2002), classe de medicamentos que se caracteriza, segundo a resolução, por sua origem exclusivamente vegetal e por não haver em sua composição princípios ativos isolados. Mesmo para essa classe mais simples, em entrevista, autoridade ligada ao setor apontou preocupação quanto à exeqüibilidade, a custos e em tempo compatíveis, dos procedimentos requeridos.

Licenças para a realização de testes em seres humanos (testes clínicos fases I e II) são concedidas pelo Conselho Nacional de Ética na Pesquisa (CONEP). Nos casos em que se pleiteia a licença de fármacos que resultaram de processos envolvendo manipulação genética, também é necessária a autorização da Comissão Técnica de Biossegurança (CTNBio).

Há, no Brasil, muito pouca experiência no licenciamento de drogas inovadoras sofisticadas. Isso talvez enseje, mais do que preocupações, a possibilidade de se instaurar, de princípio, um processo de maior operacionalidade. Para isso, seria desejável uma maior coordenação entre as esferas reguladoras, o que evitaria a prestação de informações redundantes e poderia acelerar o processo.

\subsection{O acesso à biodiversidade}

A Medida Provisória 2.186, de 16 de agosto de 2001, "dispóe sobre o acesso ao patrimônio genético, a proteção e o acesso ao conhecimento tradicional 
associado, a repartição de benefícios e o acesso à tecnologia e a transferência de tecnologia para sua conservação e utilização, e dá outras providências". Essa lei segue os princípios da Convenção sobre a Diversidade Biológica, da qual o Brasil é signatário. O decreto 3.945, de setembro de 2001, a regulamentou, estabelecendo, inclusive, os procedimentos relativos à denominada bioproscpecção, ou busca por espécies que sintetizem substâncias de potencial interesse econômico. O referido decreto criou o Conselho de Gestão do Patrimônio Genético (CGEN), que deve emitir parecer favorável para que se possam efetuar atividades de bioprospecção.

O regulamento tem por finalidade a correta fiscalização da exploração do patrimônio genético e da repartição de seus resultados. É, contudo, um dispositivo novo e ainda pouco testado quanto à sua operacionalidade. A malha organizacional para operá-lo não está ainda inteiramente constituída, o que provoca incertezas e atrasos na discussão de potenciais demandas no caso de não vir a ser rapidamente concluída.

Deve o leitor ter claro que a biodiversidade brasileira só se consubstancia como patrimônio se for, de fato, utilizada como tal. Regras e procedimento inaplicáveis ou complicados em demasia se convertem em estímulo à informalidade. No caso, a informalidade é conhecida como "biopirataria", acarretando, no limite, na perda das vantagens comparativas que a biodiversidade representa, especialmente para a indústria farmacêutica nacional, em proveito de quem dela ilegalmente se apropriar.

\subsection{O suporte público à pesquisa e o fomento à cooperação}

A criação de centros de referência na pesquisa, no desenvolvimento e na produção e acompanhamento pós-marketing de produtos farmacêuticos inovadores seria de grande utilidade na capacitação das empresas brasileiras. Essas instituições poderiam também oferecer serviços em alguns estágios de P\&D de fármacos, enquanto não há escala suficiente para permitir a sua exploração privada.

A falta de facilidades para a execução de testes pré-clínicos e clínicos no País foi apontada, em entrevista, como um dos gargalos do sistema nacional de inovação em fármacos. ${ }^{3} \mathrm{O}$ investimento nessas facilidades poderia se dar

3 Entrevista com a Dra. Eloan Pinheiro, ex-diretora de Farmanguinhos. 
nas próprias instalações dos laboratórios públicos existentes. Preocupação quanto a essa alternativa reside, contudo, nas dificuldades que essas instituições hoje enfrentam para viabilizar a cooperação, de modo ágil, com empresas privadas.

A importância de se ter uma malha de organizações dedicadas a apoiarem atividades de pesquisa e desenvolvimento e a chegada ao mercado dos seus resultados encontra eco nas políticas públicas de muitos países desde há muitos anos (Nelson, 1993; Porter, 1989). Essas organizações tomam múltiplas formas, indo desde de núcleos de transferência de tecnologia ligados a instituiçõos de pesquisa até a constituição de mecanismos multiinstitucionais de ligação entre universidade e empresa e de apoio à cooperação tecnológica empresa-empresa.

O estímulo à cooperação tem sido praticado no Brasil de diferentes formas. A experiência recente de se promover a alocação de recursos não-reembolsáveis do Fundo Nacional de Desenvolvimento Científico e Tecnológico (FNDCT) para projetos cooperativos com universidades e institutos públicos de pesquisa orientados pela demanda das empresas atende em parte a essa necessidade.

Faltam, contudo, instrumentos de apoio direto à cooperação entre empresas. A Lei 8.661/1993 chegou a criar a possibilidade de se implementarem incentivos fiscais para programas cooperativos. Sua complexidade e pouca atratividade dos incentivos, especialmente para empresas de menor porte, fizeram com que ele pouco fosse utilizado. ${ }^{4}$

A articulação de instrumentos não financeiros aos instrumentos financeiros é de grande valia na promoção da cooperação. A articulação de projetos em rede, a partir da coordenação de atores governamentais, desponta nesse caso como o instrumento mais notável. No campo do agronegócio, articulou-se, recentemente, rede de pesquisa pré-competitiva com vistas ao mapeamento do genoma do eucalipto. Estratégias similares poderiam ser articuladas pelas autoridades do campo da saúde humana, favorecendo a aproximação entre empresas em diferentes estágios de desenvolvimento, instituições públicas de pesquisa e outras instituiçóes ligadas aos diferentes níveis de governo, bancos, fundos de investimento e outros atores relevantes do sistema setorial de inovação.

4 Em verdade, apenas um Programa de Desenvolvimento Tecnológico na Indústria, coletivo, foi até hoje recomendado pela FINEP e enquadrado pelo Ministério da Ciência e Tecnologia. 


\section{A criação e o desenvolvimento de empresas de base biotecnológica, e sua organização em redes}

Os contratos diretos entre universidades ou institutos de pesquisa e empresas de grande porte são comuns desde há muito anos nos países desenvolvidos. Estas relações vêm, mais recentemente, sendo intermediadas por empresas de porte menor, fundadas no domínio de certas especialidades, conhecidas como empresas de base tecnológica. É particularmente para esse conjunto de empresas, especialmente no segmento de biotecnologia mas também em outros segmentos avançados da pesquisa farmacêutica, que se direciona a maior parte das alianças entre empresas descritas por Hullman (2000) e comentadas por Avila (2003).

Estratégias de apoio a empresas de base tecnológica são especialmente adequadas quando estão envolvidas inovações radicais (Teece, 2001), como é o caso do desenvolvimento de novos fármacos.

Contudo, as novas empresas, especialmente quando surgem diretamente das instituições de pesquisa, portanto sem a participação de empresas constituídas, enfrentam grande dificuldade em seus estágios iniciais. Seu ativo primordial, e às vezes único, é o conhecimento que acumularam e a capacidade de desenvolvê-lo mais. Enquanto não são capazes de gerar faturamento, enfrentam imensa dificuldade para arcar com os custos da pesquisa e, especialmente, do desenvolvimento dos produtos, pois seu acesso ao crédito é limitado. Nos estágios em que não é claro se haverá ou não sucesso, mesmo a capitalização por atores particularmente talhados para esse tipo de investimento, muitas vezes seria considerada arriscada demais se não fosse apoiada pelo Estado.

Além do financiamento às etapas iniciais, também a complexidade dos relacionamentos envolvidos nos negócios das empresas de alta tecnologia, contrastados à pouca estruturação das empresas introduz preocupações. Subcapitalizadas mesmo para o desenvolvimento de suas atividades centrais, tais empresas têm grande dificuldade para organizarem as informações sobre mercados e para obterem a visibilidade e o acesso necessários para com eles travarem negociação (Teece, 2001). Para fazer frente a essa natureza de dificuldades, além do suporte financeiro, apoio técnico nas áreas comercial e de gestão se fazem em geral oportunos. 
Apesar dos problemas, a avaliação que delas se faz é favorável: as empresas de menor porte têm a peculiaridade de se dedicarem a tarefas específicas e serem ágeis. Podem, assim, com mais facilidade manter-se na ponta da pesquisa tecnológica em diferentes campos. Em seu conjunto, formam uma teia de iniciativas variadas, em forma, tamanho e conteúdo, de difícil coordenação por estruturas centralizadas. Seus resultados, contudo, podem ser apropriados pelas estruturas maiores, seja pela aquisição direta dos resultados de pesquisas de interesse, seja através de contratos de prestação de serviços de pesquisa ou desenvolvimento ou de cooperação tecnológica, seja pela aquisição do controle da empresa (Teece, 2001).

No caso das cadeias de produtos farmacêuticos, os problemas inerentes aos estágios pré-operacionais são particularmente graves quando se imagina que, antes de auferir quaisquer receitas, uma empresa que descobriu um determinado princípio ativo deva cumprir todo o ciclo de inovação, sabidamente longo e progressivamente mais custoso. Estudo realizado pela divisão de produção de medicamentos da Fundação Oswaldo Cruz, Farmanguinhos, estimou em US\$ 114 milhões o custo médio do desenvolvimento de um novo produto farmacêutico, da triagem de substâncias até a chegada ao mercado do medicamento. Por sua desproporção, fomentar um tal processo é quase inimaginável, mesmo quando se o imagina em empresas já estabelecidas no setor.

Essa não é, felizmente, a única forma de se equacionar o problema. A complexidade se reduz substancialmente quando, no lugar de se procurar criar empresas integradas para desenvolver todo o processo, se busca estabecer uma malha de empresas que prestem serviços em segmentos especializados, simultaneamente para o desenvolvimento de vários novos produtos farmacêuticos.

As empresas nascentes do setor farmacêutico não são versões reduzidas, descapitalizadas e sem qualquer produto no mercado, das grandes empresas integradas do setor. As empresas que celebram contratos como os descritos por Hulmann (2000) são prestadoras de serviços tecnológicos avançados que se encadeiam em relacionamentos não exclusivos de fornecimento, e auferem resultados mesmo sem jamais ter participado do desenvolvimento de uma única droga já disponível no mercado.

Como demonstram os trabalhos empíricos coordenados por Jungmittag et al. (2000), essa teia de iniciativas descoordenadas constitui importante fonte 
de serviços na cadeia da pesquisa e do desenvolvimento de fármacos. Do ponto de vista das grandes empresas, saber movimentar-se nela, buscando oportunidades alinhadas aos seus objetivos estratégicos e firmando contratos que possibilitem o seu aproveitamento e a dosagem equilibrada de riscos e retornos constitui, no novo paradigma tecnológico do setor, diferencial competitivo. Ao lado da organização interna da produção e transferência de conhecimento, essa preocupação ocupa posição central em uma disciplina do campo da gestão que ganhou popularidade nos últimos anos: a inteligência competitiva, ou gestão do conhecimento.

Do ponto de vista dos formuladores de políticas, tais empresas funcionam como vetores entre a produção de conhecimento e as empresas estabelecidas. Quando olhadas sob esse prisma, o custo de apoiar seu desenvolvimento pode ser considerado reduzido.

Quando se adensam as iniciativas dessa natureza, em malhas articuladas de empresas fortemente integradas tanto à demanda exigente das grandes companhias quanto à produção de conhecimento em universidades e institutos de pesquisa, conformam-se os arranjos locais dinâmicos, ou clusters. Na visão de Porter (1989), essas concentrações, ao favorecerem a troca de experiências com grande intensidade, dinamizam o ambiente econômico e tornam-se os motores da inovação nos segmento de ponta.

Os Estados Unidos foram os pioneiros na adoção de medidas fortes de fomento a este tipo de empresas. Gorgulho (1996) apontou que a atividade de capital de risco ganhou importância a partir da promulgação, em 1958, do Small Business Investiment Act, que autorizou a criação das companhias de investimentos em pequenas empresas, denominadas Small Business Investment Companies (SBICs), e lhes concedeu condições favorecidas.

As estruturas de fomento aos empreendimentos nascentes cresceram, diversificaram-se e se especializaram continuamente nos Estados Unidos desde então. Fundos de capital de risco tornaram-se especializados setorialmente e por estágio de desenvolvimento das empresas (Gorgulho, 1996), com o objetivo de oferecer serviços de informação e suporte de mais alta qualidade. Inúmeras instituições e empresas foram criadas com o mesmo objetivo.

A partir da experiência norte-americana, outros países remodelaram suas estruturas de suporte a empresas nascentes de base tecnológica, destacando-se Israel, 
França e outros países europeus e alguns países do sudoeste asiático, como a Coréia e Taiwan (ver, p.ex., Avila, 2003; Teece, 2001; Gorgulho, 1996; Nelson, 1993). Caracterizam essas experiências a combinação criativa de instrumentos financeiros e não-financeiros que visam não apenas viabilizar a criação de empresas de base tecnológica, como a sua interação em rede com empresas congêneres e empresas e instituições complementares de distintos portes e propósitos, de modo a construir sinergias e obter dinamismo. Na América Latina também houve experiências importantes de relativo sucesso. Cuba, particularmente, desenvolveu sofisticado sistema que objetiva conectar seu sistema público de pesquisa em vacinas, fármacos e equipamentos para a saúde à indústria farmacêutica internacional, valendo-se de empresas estatais a jusante dos centros de pesquisa, que atuam como elos de ligação. ${ }^{5}$ No Brasil, o BNDES (Banco Nacional de Desenvolvimento Econômico e Social), através da experiência do CONTEC (Conselho Estadual de Ciência e Tecnologia) (Gorgulho, 1996) e, mais recentemente, com o Profarma (www.bndes.gov.br), e a FINEP (Financiadora de Estudos e Projetos), com o Projeto Inovar, vêm criando mecanismos integrados de fomento com características semelhantes às dos sistemas americano e europeu (Avila, 2003).

O sucesso de tais iniciativas no campo farmacêutico parece requerer, contudo, iniciativas focadas, especialmente em países onde, como no Brasil, não há tradição de inovação farmacêutica. Um conjunto de ações semelhantes às acima descritas pode ser desenvolvido com foco exclusivo na formação de malhas de empresas inovadoras atuantes em segmentos tais como: desenvolvimento de alvos; prospecção de biodiversidade e síntese combinatória de substâncias químicas; triagem de substâncias, síntese e combinação de princípios ativos; serviços de biotérios e realização de testes pré-clínicos e clínicos; serviços de consultoria especializados para aumento de escala e melhores práticas laboratoriais e de manufatura, dentre outros.

Como demonstram as experiências, o público-alvo prioritário das ações contidas numa tal estratégia não é constituído apenas por empresas de base tecnológica, mas por todos os atores sociais que podem se articular para criar novas empresas ou apoiá-las em seu nascimento e desenvolvimento, para os quais se podem desenvolver instrumentos especializados de incentivo.

5 A empresa estatal Biomundi reúne informações sobre todo o sistema, e pode ser acessada através dos consulados e escritórios comerciais de Cuba. 
A experiência internacional consagrou a subvenção, o capital de risco de origem estatal e os derivativos mitigadores de riscos como os instrumentos dos mais eficazes para motivar a capitalização de empresas nascentes e emergentes (ou em fase de expansão) de base tecnológica. A criação dos Fundos Setoriais (como são conhecidos os programas contido no Orçamento Geral da União OGU), que alocam recursos ao FNDCT para o financiamento das atividades de pesquisa e desenvolvimento em segmentos ou com propósitos específicos), pode representar uma fonte regular para o desenvolvimento de iniciativas que visem a fomentar o adensamento de malhas dinâmicas de empresas de base tecnológica no campo farmacêutico, viabilizando a construção e a operação regular de tais instrumentos. Acresça-se a isso que a Lei 10.332/2001 criou a possibilidade de se subvencionar diretamente o Programa de Desenvolvimento Tecnológico (Industrial - PDTI, ou Agropecuário - PDTA) de empresas, iniciativa que deverá ser fortalecida com o conjunto de iniciativas que compõem a nova Política Industrial, Tecnológica e de Comércio Exterior (as diretrizes da PITCE podem ser consultadas em www.ipea.gov.br).

Existem no País duas incubadoras especializadas em Biotecnologia e áreas afins: a BioRio (www.biorio.com.br) e a BioMinas (www.biominas.com.br). Essas estruturas podem ser aperfeiçoadas e sua experiência multiplicada para outras localidades com potencial para o desenvolvimento dessas atividades. ${ }^{6}$

Dispositivos para favorecer a reestruturação das empresas (fusões, aquisições, abertura de capital) seriam importante acréscimo ao quadro de instrumentos de fomento ao desenvolvimento de empresas de base biotecnológica no País. Ações que fomentassem a participação de empresas estruturadas do setor em fundos de capital de risco podem ser especialmente desenvolvidas. Esse segmento de investidores representa, em outros países, importante fonte de capital de risco, conhecida no mercado como Corporate Venture Capital. No Brasil, companhias com a Vale do Rio Doce e a Votorantim criaram fundos com essa característica, tendo este último foco específico no financiamento de empresas de biotecnologia no Brasil. A participação de empresas do setor farmacêutico em fundos como esses os tornaria particularmente interessantes,

\footnotetext{
6 Foi instituído, embora ainda não esteja operacional, o Centro de Biotecnologia da Amazônia, com sede em Manaus. Esse centro tem como missão promover o aproveitamento da biodiversidade amazônica especialmente em aplicações farmacêuticas.
} 
pois além dos recursos financeiros, essas empresas, interessadas no desempenho dessas carteiras, teriam estímulo para emprestarem seu prestígio e conhecimento dos mercados às empresas investidas. Em alguns casos poderiam representar, ainda, potencial mercado para os serviços das novas empresas e naturais compradores das ações de empresas bem-sucedidas detidas pelos fundos, facilitando a realização de resultados pelos seus demais cotistas.

Outra oportunidade para a participação de empresas mais estruturadas pode ser desenvolvida nas fases intermediárias do desenvolvimento de fármacos inovadores, a partir dos resultados de institutos de pesquisa ou de empresas dedicadas à triagem, brasileiras ou de qualquer outra nacionalidade. Estes atores buscam, preferencialmente, licenciar o que desenvolvem junto às grandes companhias multinacionais, essencialmente por ser essa a alternativa que introduz menores riscos comerciais e maiores probabilidades de suporte financeiro para desenvolvimento futuro. Note-se, contudo, que a falta de tradição e os custos de transação muitas vezes impedem que pequenas empresas brasileiras se apresentem adequadamente a potenciais parceiros internacionais de grande porte (Teece, 2001).

A constituição de pólos agregadores de potenciais e iniciativas em empresas de porte médio (como algumas das hoje dedicadas ao segmento de genéricos) pode representar, nessas situaçôes, alternativa que viabilize esse tipo de negociação, possivelmente com maior agregação de valor. Não está descartada, tampouco, a possibilidade de se construírem condições de atratividade para o licenciamento por empresas brasileiras de patentes detidas por pequenas empresas estrangeiras. Essas condições podem ser construídas mediante o fomento à associação entre empresas de base tecnológica de qualquer procedência e empresas nacionais, mediante ou não a cooperação com instituições públicas de pesquisa nacionais. As empresas de médio porte brasileiras poderiam mesmo ser apoiadas para adquirir empresas estrangeiras de interesse estratégico. ${ }^{7}$ A síntese de fármacos sob licença dessas instituições e empresas estrangeiras poderia, evidentemente, contar com a cooperação do licenciador, o que a tornaria mais simples de desenvolver do que mesmo a geração de rotas de síntese de genéricos.

O apoio a empresas de pequeno porte, de um modo geral, só se torna relevante quando se é capaz de fazê-lo em grande escala. No caso de se promo-

O fomento à aquisição de empresas no exterior surgiu como possibilidade na discussão em torno das políticas operacionais da FINEP travadas ao longo de 2001 (Avila, 2003). 
verem empresas de pequeno porte em segmentos dinâmicos, a esse constrangimento quantitativo se agregam consideraçôes qualitativas. Apenas uma malha de pequenas empresas, articuladas entre si, com empresas de porte maior e com outros atores, é capaz de atender aos objetivos que aqui se propóem, que podem ser sintetizados na criação de um ambiente de inovação no campo farmacêutico. A condução de um programa de fomento ativo é, inteiramente dependente de uma real capacidade de articulação, coordenação e mobilização de um tal conjunto de atores. ${ }^{8}$

\section{A integração às redes mundiais de desenvolvimento e comercialização de produtos farmacêuticos inovadores}

Promover a articulação de empresas inovadoras brasileiras ao mercado por seus produtos e serviços é parte integral de uma estratégia que vise fomentar seu surgimento e desenvolvimento. As empresas brasileiras de grande porte, atuantes muitas vezes na formulação de medicamentos e na comercialização no mercado brasileiro, podem vir a desempenhar importante papel de ligação entre essas empresas e as multinacionais que controlam os canais de acesso aos principais mercados estrangeiros.

Apoiar uma tal organização, possivelmente através do poder mobilizador do Estado pode ser relevante. Ações de apoio à organização empresarial, com o fim principal de articulação de produtores à demanda, mas também com vistas às demais finalidades acima referidas, foram realizadas no País para outros setores de atividades.

O exemplo mais recente foi a criação da Organização Nacional da Indústria do Petróleo (ONIP - www.onip.org.br), apoiada pela Agência Nacional do Petróleo (ANP), pelo BNDES e pela FINEP, além da Petrobras. A experiência da ONIP, que é uma associação de associações com interesse na indústria do petróleo, tem permitido a discussão de metas para a participação da indústria nacional no

8 Castro e Avila (2004) argumentam que a nova PITCE se alicerça no reconhecimento da inovação como a dimensãochave para que as empresas brasileiras desenvolvam o potencial que acumularam nos últimos anos. Constatam, contudo, que políticas de tal natureza são necessariamente mais complexas do que as até então praticadas no País, por adicionarem a capacitação e a troca de conhecimentos à preocupação com o aumento da capacidade produtiva. Segundo essa visão, alinhada ao que aqui se preconiza para viabilizar a inovação farmacêutica no País, o principal desafio da nova PITCE (que tem, explicitamente, entre suas prioridades o setor farmacêutico) é a coordenação dos dispositivos de capitalização e financiamento aos demais mecanismos disponíveis ou em desenvolvimento, de modo a estabelecer um sistema mais completo e coerente de indução. 
fornecimento à Petrobras e aos operadores entrantes, assim como a formulação de estratégias para viabilizá-las, que vão desde a maior capacitação das empresas até o estabelecimento de cotas mínimas para o fornecimento local.

Um conjunto de iniciativas para o setor farmacêutico, complementares às ações mais usuais de promoção comercial, poderia se inspirar no exemplo da ONIP. Seria necessário observar a diferença fundamental de que, neste caso, não se encontra no País a maior demanda que se pretende suprir, o que torna inócuo o estabelecimento de cotas ou mecanismos similares. Seguem válidas, contudo, as iniciativas voltadas para o aprendizado coletivo, a interlocução organizada com empresas e associações no exterior e a discussão de mecanismos reguladores específicos, que podem chegar a incluir os aspectos críticos mencionados na primeira seção deste artigo (propriedade intelectual, acesso à biodiversidade e registros e licenças para fármacos inovadores).

O poder de compra do Estado também pode ser utilizado para a inserção comercial e para a promoção da cooperação tecnológica entre as empresas brasileiras e mesmo com empresas internacionais. Note-se que as importações do Estado brasileiro de produtos para a área da defesa têm sido feitas mediante contratos cuidadosamente desenhados, que incluem compensaçôes comerciais, conhecidas como offsets e também praticadas por outros países. ${ }^{9}$

As compensações comerciais oferecidas são analisadas nas licitações internacionais, em adição às condições técnicas e econômico-financeiras do fornecimento proposto. Originalmente as compensaçôes comerciais foram concebidas para equilibrar a balança de pagamentos e reduzir as necessidades de moeda forte nas transações entre países que não as emitem. Incumbia-se o vendedor de encontrar, em seu país, comprador para algum produto do país a que se destinava a sua venda. Contratos com esse desenho foram feitos, por exemplo, na aquisição de produtos chineses pelo Instituto Nacional de Pesquisas Espaciais (INPE) com recursos do FNDCT.

Mais recentemente, a natureza das compensações se diversificou em propósitos e em instrumentos. Entre as novas formas de compensação incluemse a oferta de licenças para o uso de tecnologias protegidas, assistência técnica,

9 Restrições à prática de offsets constam do acordo de compras governamentais da OMC, do qual o Brasil e a maioria dos países em desenvolvimento não são signatários. Propostas pelos Estados Unidos nas negociações da ALCA, (Associação de Livre Comércio das Américas) técnicos do Itamaraty avaliam que essas restrições dificilmente serão aceitas pelos países latino-americanos no acordo final. 
compromissos de investimento direto, de participação em empreendimentos conjuntos (joint-ventures), ou de cooperação tecnológica e comercial com empresas nacionais, e mesmo a participação financeira em fundos de capital de risco. Esta última alternativa ocorre, em geral, em setores afins ao da empresa fornecedora, que garante, assim, interesse pelo desempenho comercial dos empreendimentos que venham a ser investidos pelos fundos e tem meios efetivos de apoiá-lo.

Todas essas formas podem ser tentadas nas importações de produtos farmacêuticos pelo Sistema Único de Saúde (SUS). Seu foco seria, naturalmente, a aproximação das empresas brasileiras às empresas que coordenam o desenvolvimento de novos fármacos e controlam a sua distribuição e comercialização no mercado mundial. A grande dificuldade a contornar, de natureza institucional, diz respeito à forma de licitar e contratar o fornecimento de produtos farmacêuticos. Offsets são negociados com maior facilidade em contratos de grande volume e prazo longo. Sua exigência introduz complexidade na avaliação das propostas e a necessidade do acompanhamento da execução do que vier a ser contratado. Se desalinhados do interesse dos fornecedores, podem acarretar aumento nos preços de fornecimento, o que acarretaria despesas adicionais para o sistema de saúde.

Além dos offsets, ações e instrumentos visando à atração de atividades de P\&D de empresas multinacionais para o País também podem ser articuladas. A proximidade é um atributo que tem relevância no estabelecimento de parcerias tecnológicas, como demonstra a extensa literatura sobre clusters e arranjos locais de produção (Nelson, 1993). Instrumentos geralmente empregados para a atração de investimentos, como incentivos fiscais e financiamentos em condições privilegiadas podem ser empregados neste campo (Chang, 2003). A articulação desses instrumentos com cláusulas de compensação no eventual fornecimento ao SUS pode aumentar as chances de com eles se auferirem resultados, assim como a oferta de contratos para o desenvolvimento de pesquisas para o desenvolvimento de medicamentos prioritários. $\mathrm{O}$ acesso à infra-estrutura pública de $P \& D$ de alta qualidade aumenta a atratividade dos investimentos em centros de P\&D dessas empresas no País, assim como o fazem incentivos especiais à cooperação tecnológica com empresas brasileiras (Porter, 1989).

As maiores dificuldades para o estabelecimento de um ambiente dinâmico 
estão nas etapas iniciais, quando ainda não há densidade de iniciativas dessa natureza em operação (Gorgulho, 1996). Nesse estágio, a falta de experiência das instituições nacionais e a ausência de casos bem-sucedidos que demonstrem a viabilidade do que é proposto aumentam enormemente a percepção de risco por parte dos atores, especialmente dos mais distantes da realidade nacional e de suas intenções e práticas de fomento, como são as empresas multinacionais.

Instrumentos mais fortes precisam ser operados nesse estágio para todos os atores (Chang, 2003). Dois grandes atrativos podem ser formulados para conferir atratividade inicial aos investimentos em P\&D seja por empresas brasileiras seja por empresas multinacionais: a demanda pública pelo desenvolvimento de drogas prioritárias em larga escala e o acesso à biodiversidade brasileira. A demanda poderia ser gerada a partir do fortalecimento do Programa de Desenvolvimento de Medicamentos para Doenças Negligenciadas, conduzido por uma rede de instituições da qual fazem parte laboratórios públicos brasileiros (ver, p.ex., www.msf.org).

A prospecção da biodiversidade e sua manipulação genética tocam em problemas sensíveis. Utilizar a autorização para executar essas atividades como fator de indução ao investimento requer toda sorte de cuidados, a começar pelo efetivo controle do que é feito à margem das intenções e restriçōes oficiais. Representa, contudo, o mais evidente diferencial que o País possui para a motivação de investimento no campo farmacêutico e, deve, portanto, ser utilizado em favor da economia do País e do bem estar de sua população.

\section{Conclusão}

As principais conclusões deste trabalho são: (1) face às condições da economia brasileira e à natureza de sua inserção na economia global, o objetivo da política para o complexo farmacêutico não precisa nem deve ser a simples e generalizada substituição de importações, mas sim a construção, no País, de um ambiente de inovação farmacêutica capaz de oferecer produtos e serviços avançados para o mercado global; (2) face às novas estratégias de P\&D das empresas líderes mundiais do setor, que abrem oportunidades para empresas de porte menor, e à capacitação científica e tecnológica nacional, esse objetivo é alcançável mediante ações de indução e facilitação, apesar de exigir do Estado um 
nível de coordenação bastante mais elevado do que aquele que é necessário para a promoção de investimentos em segmentos maduros.

Para tanto, apresentou-se proposta que se centra no aproveitamento da dispersão das atividades de P\&D das grandes empresas de atuação internacional, conforme sustentado em Jungmittag et al. (2000). Em linha com a natureza dessa dispersão, mormente realizada através da contratação de empresas de base tecnológica para a realização de partes de alto valor agregado das atividades de $\mathrm{P} \& \mathrm{D}$, o fomento ao desenvolvimento de uma teia de empresas, de alta especialização e não integradas, e ao relacionamento desta teia com empresas dotadas de capacidade comercial, constitui seu eixo unificador.

De uma tal teia se pode esperar, e fomentar, que atue como vetor de acesso bidirecional, da pesquisa nacional de novos fármacos (cooperativamente pública e privada) ao capital nacional e às empresas multinacionais e, complementarmente, da indústria nacional à pesquisa, pública ou cooperativa, nacional e internacional.

A partir dessa visão integradora, a estratégia proposta operaria em três dimensões complementares: o desenvolvimento de um ambiente favorável à inovação farmacêutica; o desenvolvimento de redes de empresas de base tecnológica no campo farmacêutico; e o desenvolvimento de canais entre as empresas nacionais e as multinacionais que atuam no mercado de drogas inovadoras. Apresentaram-se caminhos e instrumentos para viabilizar a ação em cada uma dessas dimensóes, tendo-se destacado a importância de se assegurar a maior coordenação possível entre os atores envolvidos e os instrumentos empregados, financeiros e não financeiros, que devem ser entendidos como complementarmente necessários face à complexidade dos objetivos. Propôsse, finalmente, que se utilize o Programa de Desenvolvimento de Medicamentos para Doenças Negligenciadas como piloto articulador de uma iniciativa integrada de fomento à inovação farmacêutica, provendo-se cuidados apoio à prospecção e à catalogação da diversidade biogenética como um dos elementos estruturantes da iniciativa.

Como conseqüência imediata das considerações tecidas ao longo deste trabalho, sugere-se, como pauta relevante para pesquisa futura, investigar a existência de sinergias entre a atuação no mercado de genéricos, assim como em cosméticos, e as atividades envolvidas no desenvolvimento, produção, marketing 
e comercialização de produtos farmacêuticos inovadores. Se existirem, na forma de vasos comunicantes financeiros e comerciais, talvez, aí sim, abra-se caminho para, no longo prazo, se romper a barreira à entrada estabelecida no grande oligopólio farmacêutico de escala global.

\section{Referências bibliográficas}

Arora, A. et al., The Nature and the Extent of the Market for Technology in Biopharmaceuticals, mimeo, 2000.

Avila, J., "Políticas Ativas para o Desenvolvimento do Setor Farmacêutico Brasileiro: Oportunidades e Bases Conceptuais para a sua Formulação", Tese de Doutorado, Instituto de Medicina Social, Rio de Janeiro: UERJ, 2003.

Castro, A., "A Rica Fauna da Política Industrial e a Sua Nova Fronteira", in Revista Brasileira de Inovação, vol.1, n.2, jul-dez, p.253-274, 2002.

, A Economia Brasileira em Marcha Forçada, Forense Universitária, Rio de Janeiro, 1985.

; Avila, J., "Uma Política Industrial e Tecnológica Baseada no Potencial das Empresas", in Fórum Nacional 2004 (no prelo), Rio de Janeiro, 2004.

Chang, H., Globalization, Economic Development and the Role of the State, Penang: Zed Books, 2003.

Frenkel, J., Estudo da Competitividade de Cadeias Integradas no Brasil: Impacto das Zonas de Livre Comércio. Cadeia: Farmacêutica, Ministério do Desenvolvimento, Indústria e Comércio Exterior, Brasília, 2002.

Gorgulho, L., O Capital de Risco como Alternativa de Apoio às Pequenas Empresas de Base Tecnológica: O Caso CONTEC/BNDES, Tese de Mestrado do Instituto de Economia, Rio de Janeiro: UFRJ, 1996.

Hullman, A., "Generation, Transfer and Exploitation of New Knowledge”, in Junmittag et al., Changing Innovation in the Pharmaceutical Industry, Nova York: Springer-Verlag, 2000.

Jungmittag, A. , “The National System of Innovation in the United States and Germany”, in Jungmittag et al., Changing Innovation in the Pharmaceutical Industry, Nova York: SpringerVerlag, 2000.

; Reger, G., "Dynamics of the Market and Market Structure", in Jungmittag, A. et al., Changing Innovation in the Pharmaceutical Industry, Nova York: Springer-Verlag, 2000. 
et al. (org), Changing Innovation in the Pharmaceutical Industry, Nova York: SpringerVerlag, 2000.

McKelvey, M.; Orsenigo, L., Pharmaceuticals as a Sectoral Innovation System, Working Paper Essay, 2001 (http://www.cespri.uni-bocconi.it/essay/wpapers.htm)

Magalhães, L. C. et al., Estratégias Empresariais de Crescimento na Indústria Farmacêutica Brasileira: Investimentos, Fusões e Aquisiçōes, 1988-2002, Texto para Discussão IPEA no 995, Brasília, 2003.

Malerba, F.; Orsenigo, L., Innovation and Market Structure in the Dynamics of the Pharmaceutical Industry and Biotechnology: Towards a History Friendly Model, DRUID Nelson and Winter Conference, Aalborg, 2001.

Nelson, R. (org.) National Systems of Innovation: a Comparative Study, Oxford: Oxford University Press, 1993.

Porter, M., A Competitividade das Nações, Rio de Janeiro: Editora Campus, 1989.

Queiroz, S., Os Determinantes da Capacitação Tecnológica no Setor Químico-Farmacêutico Brasileiro, Tese de Doutoramento, Campinas: UNICAMP, 1993.

Salles-Filho, S., Ciência, Tecnologia e Inovação: A Reorganização da Pesquisa Pública no Brasil, Campinas: Editora Komedi, 2000.

Teece, D., Managing Intellectual Capital, Nova York: Oxford University Press, 2001.

\section{Bibliografia complementar}

Campos, A. M., et al., "Avaliação de Agências Reguladoras: uma Agenda de Desafios para a Sociedade Brasileira” in Revista de Administração Pública, 34/5, 29-46, 2000.

Chang, H., The Political Economy of Industrial Policy, Nova York: McMilan Press, 1994.

Coutinho, L., Estudo de Competitividade de Cadeias Integradas no Brasil: Impactos das Zonas de Livre Comércio, Ministério do Desenvolvimento da Indústria e do Comércio Exterior, 2002.

DND Working Group. Desequilibrio Fatal: A Crise em Pesquisa e Desenvolvimento de Drogas para Doenças Negligenciadas. Médicos Sem Fronteiras, 2001.

Dosi, G., Technical Change and Industrial Transformation, Londres: MacMillan, 1994.

Freitas, M. C., Financiamento do Desenvolvimento Tecnológico: uma Análise Comparada, Convênio FINEP-FUNDAP, São Paulo, mimeo, 2001.

Gadelha, C., Estudo de Competitividade das Cadeias Produtivas: Setor Farmacêutico, Ministério do Desenvolvimento, Indústria e Comércio Exterior, Brasília, mimeo, 2002.

Lerner, J., The government as venture capitalist: the long run impact of the SBIR program, Cambridge, MA: National Bureau of Economic Research, 1996. (NBER Working Paper Series. WP 5753) 
Lundvall, B., National Systems of Innovation, Londres: Pinter, 1992.

Machado, S. et al., MPEs de Base Tecnológica: Conceituação, Formas de Financiamento e Análise de Casos Brasileiros, SEBRAE-RJ, Rio de Janeiro, 2001.

Magalhães, L. C., Evolução e Tendências da Balança de Comércio Exterior da Indústria Farmacêutica na Década de 90. VI Encontro Nacional de Economia da SAÚDE - ABRES, 2002.

Metcalfe, J. S., Evolutionary Economics and Creative Destruction, Londres: Routledge, 1998.

Mintzberg, H.; Quinn, J. (orgs.), Readings on the Strategy Process, Upper Saddle River: Prentice Hall, 1998.

Pammolli, F.; Riccaboni, M., Technological Competencies in Networks of Innovators: The Case of Biopharmaceuticals, EPRIS Program, mimeo, 2000.

Pavitt, K., "Sectoral Patterns of Technical Change: Towards a Taxonomy and a Theory”, in Research Policy, 13. 343-73, 1984.

Possas, M., "Elementos para uma Integração Microdinâmica na Teoria do Desenvolvimento Econômico", in Revista Brasileira de Inovação, vol.1, n.1, jan.-jun., p.123-49, 2002.

, A Dinâmica da Economia Capitalista: uma Abordagem Teórica, São Paulo: Brasiliense, 1987.

Queiroz, S.; Gonzáles, A. J. V., “Mudanças Recentes na Estrutura Produtiva da Indústria Farmacêutica”, in Negri, B.; Giovanni, G. di, (orgs.), Brasil: Radiografia da Saúde, Campinas: Unicamp, Instituto de Economia, 2001.

Reger, G.; "Internationalization of Research and Development in Pharmaceuticals, in Jungmittag et al., Changing Innovation in the Pharmaceutical Industry, Nova York: Springer-Verlag, 2000.

Reiss, T.; Rinze, S., "Innovation Process and Techno-Scientific Dynamics”, in Jungmittag, A. et al., Changing Innovation in the Pharmaceutical Industry, 2000.

Sharpe, W., Investments, Englewood Cliffs: Prentice Hall, 1990.

Silva, R., Indústria Farmacêutica Brasileira: Estrutura e a Questão de Preços de Transferência, Tese de Doutoramento, Rio de Janeiro: UFRJ, 1999.

Temporão, J., O Complexo Industrial da Saúde Público e Privado: A Produção e o Consumo de Vacinas no Brasil, Tese de Doutoramento, Rio de Janeiro: Instituto de Medicina Social, UERJ, 2002.

Wilkinson, J., Estudo da Competitividade de Cadeias Integradas no Brasil. Impacto das Zonas de Livre Comércio. Cadeia: Biotecnologia e Agronegócios, Brasília: Ministério do Desenvolvimento, Indústria e Comércio Exterior, 2002. 